\title{
The authors' response
}

\author{
Ofer Sadan *i] and Owen Samuels
}

\begin{abstract}
In response to comments raised, we acknowledge the shortcomings of our study. It is a small study. However, it is a pilot study, which is not meant to create generalizable data, rather to explore new potential directions. To this end, our conclusions were clearly supported by the results. We demonstrated that administration of $16.4 \% \mathrm{NaCl} / \mathrm{Na}-$ acetate solution was feasible, safe, and was associated with lower rates of AKI. We share the call that large RCTs are required to follow this pilot study and hope that our data will stimulate the ongoing discussion regarding the role of chloride in AKI mechanism.
\end{abstract}

Keywords: Cerebral edema, Subarachnoid hemorrhage, Hyperosmolar therapy, Hyperchloremia, Acute kidney injury, Neurocritical care

To the editor,

We appreciate the interest in our manuscript [1], and the opportunity to respond to the comments. There is no doubt that our study suffers from several shortcomings. It is a small study, and even smaller than planned due to limitations that were not always in our control. However, it is a pilot study, as the title mentioned. Pilot studies are not meant to create generalizable data, rather to explore new potential directions. We believe that our study accomplished that goal.

To our knowledge, our study is the first of its kind, presenting high-quality prospective data, which demonstrated the feasibility and potential safety of an alternative hypertonic solution. Although our study was underpowered to reach its primary endpoint, the results did point to our hypothesized direction. This phase 1type research is the beginning, not the end of the clinical investigation, and should be viewed and our findings considered preliminary in nature.

The patients at our ICU are often treated according to sodium goals in order to improve intracranial compliance. Therefore, using less doses suggests that we were

This reply refers to the comment available at https://doi.org/10.1186/s40560020-00492-x.

* Correspondence: ofer.sadan@gmail.com

Department of Neurology and Neurosurgery, Division of Neurocritical Care, Emory University Hospital, 1364 Clifton Rd. NE, Atlanta, GA 30322, USA able to reach the goal more efficiently with the alternative solution, not that these patients had less edema. As for the delta creatinine, we reported that the majority of AKI events met the criteria of KDIGO 1, which means a small change in creatinine, or reduced urine output. Therefore, it is of no surprise that the change in creatinine was undetected in such a small group of patients.

We agree that there are likely additional factors that could have been considered in the analysis, such as vasopressor use, and perhaps specific nephrotoxins. However, when dealing with a small cohort, having too many competing variables will mask any effect, simply from a statistical-mathematical calculation standpoint. In a larger trial, additional factors will be considered.

The timing of AKI did surprise us. We designed the study in such a way that only patients at higher risk of hyperchloremia-associated AKI would be randomized. With this intent, patients were randomized only when mild hyperchloremia was measured. With the clarity of hindsight, it would have been better if we would have randomized patients earlier, since the temporal relationship between hyperchloremia and AKI was shorter than expected.

We would like to thank the comment regarding Fig. 3b. Indeed, this was a mistake. We did have 9 patients who developed $\mathrm{AKI}$ in the $\mathrm{NaCl}$ group yet presented only 8 in 


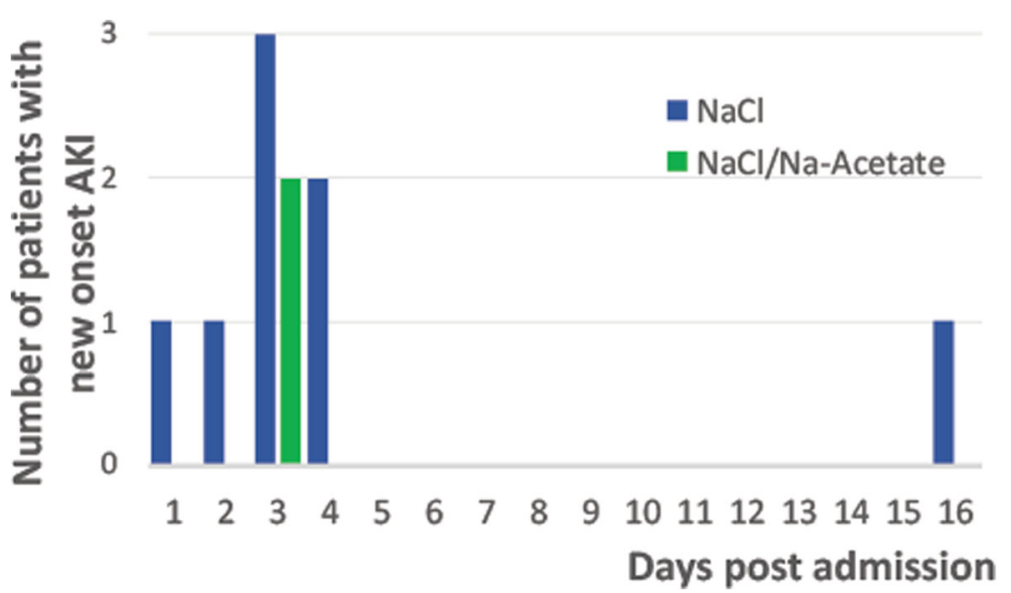

Fig. $\mathbf{3} \mathbf{b}$ Histogram of AKI frequency by group of treatment and hospitalization day

that graph. We apologize for this mistake, and an erratum with the corrected graph was published.

Overall, despite the intrinsic limitation of a small randomized pilot study, we believe our conclusions were clearly supported by the results. We demonstrated that administration of $16.4 \% \mathrm{NaCl} / \mathrm{Na}$-acetate solution was feasible, safe, and was associated with lower rates of AKI. We share the call that large RCTs are required to follow this pilot study and hope that our data will stimulate the ongoing discussion regarding the role of chloride in AKI mechanism.

\section{Abbreviations}

ICU: Intensive care unit; AKI: Acute kidney injury

\section{Acknowledgements}

Not applicable

\section{Declarations}

The study was conducted with adherence to ethical guidelines, was approved by the Emory University (Atlanta, GA, USA) IRB, and informed consent was obtained from all the participants (or their LAR) as detailed in the manuscript.

\section{Authors' contributions}

OS-writing and finalizing the text. The author(s) read and approved the final manuscript.

\section{Funding}

The study is funded in part by PHS grant UL1TR000454 from the Clinical and Translational Science Award program, National Institutes of Health, and the National Center for Advancing Translational Sciences. The funding body did not have a role in the design of the study and collection, analysis, and interpretation of data and in writing the manuscript.

\section{Availability of data and materials}

The datasets used and/or analyzed during the current study are available from the corresponding author on reasonable request.

\section{Consent for publication}

Not applicable

\section{Competing interests}

The authors declare that they have no competing interests.
Received: 3 September 2020 Accepted: 10 September 2020 Published online: 26 September 2020

\section{Reference}

1. Sadan O, Singbartl K, Kraft J, et al. Low-chloride- versus high-chloridecontaining hypertonic solution for the treatment of subarachnoid hemorrhage-related complications: the ACETatE (a low ChloriE hyperTonic solution for brain edema) randomized trial. J Intensive Care. 2020;8:32.

\section{Publisher's Note}

Springer Nature remains neutral with regard to jurisdictional claims in published maps and institutional affiliations.
Ready to submit your research? Choose BMC and benefit from:

- fast, convenient online submission

- thorough peer review by experienced researchers in your field

- rapid publication on acceptance

- support for research data, including large and complex data types

- gold Open Access which fosters wider collaboration and increased citations

- maximum visibility for your research: over $100 \mathrm{M}$ website views per year

At BMC, research is always in progress.

Learn more biomedcentral.com/submissions 